\title{
Adsorption and reduction of nitrate in water on hydrotalcite-supported $\mathrm{Pd}-\mathrm{Cu}$ catalyst
}

\author{
Ying Wang ${ }^{\text {a,b }}$, Jiuhui $\mathrm{Qu}^{\mathrm{a}, *}$, Huijuan Liu ${ }^{\text {a }}$, ChengZhi $\mathrm{Hu}^{\text {a,b }}$ \\ ${ }^{a}$ State Key Laboratory of Environmental Aquatic Chemistry, Research Center for Eco-Environmental Sciences, \\ Chinese Academy of Sciences, Beijing 100085, China \\ ${ }^{\mathrm{b}}$ Graduate School of Chinese Academy of Sciences, Beijing 100039, China
}

Available online 20 July 2007

\begin{abstract}
The hydrotalcite-supported Pd-Cu catalysts were successfully prepared by the impregnation or coprecipitation method, and their adsorption and catalytic reduction activity for nitrate in water were evaluated. The catalysts were characterized by X-ray diffraction (XRD) and surface area (BET) analysis. The results demonstrated that hydrotalcite-supported $\mathrm{Pd}-\mathrm{Cu}$ catalysts could significantly adsorb nitrate ions, and then, effectively catalytically reduce them. The excellent adsorption ability for nitrate resulted from the regenerated layer structure of calcined hydrotalcite catalyst in nitrate aqueous solution. Nitrate was forced into the interlayer space and adsorbed on the external surface. The adsorption kinetics and the adsorption isotherm could be well described by pseudo-second-order model and the Langmuir model, respectively. The comparison of catalytic reduction with the adsorption for nitrate indicated that catalytic hydrogenation activity for nitrate increased with increasing adsorption capacity; nitrate reduction on hydrotalcite-supported $\mathrm{Pd}-\mathrm{Cu}$ catalysts was a consecutive and dynamic adsorption and catalytic hydrogenation process. In addition, the catalyst obtained by coprecipitation method, with intact regeneration of hydrotalcite structure and a high dispersion of active metals, hold higher adsorption and catalytic activity than that prepared by co-impregnation method.
\end{abstract}

(C) 2007 Elsevier B.V. All rights reserved.

Keywords: Nitrate reduction; Catalytic; Adsorption; Hydrotalcite

\section{Introduction}

In recent years, nitrate concentration in groundwater has been increasing in many parts of the world due to increased usage of nitrogenous fertilizers and discharge of domestic and industrial wastewater. In China, nitrate concentration in some drinking water source is higher than $30 \mathrm{mg}^{-\mathrm{N} \mathrm{L}^{-1}}$, which exceeds the standard set (lower than $10 \mathrm{mg}-\mathrm{N} \mathrm{L}^{-1}$ ) reported by World Health Organization [1]. Nitrate can cause methemoglobinemia when ingested by infants, and they can even cause carcinoma, malformation and mutation when transformed into nitrosoamines [2].

In this respect, the current technologies used for nitrate removal from water receive an increasing attention. Available methods include physical-chemical [3], biological [4,5] and catalytic processes [6,7]. Physical-chemical process, such as

\footnotetext{
* Corresponding author. Tel.: +86 10 62849151; fax: +86 1062923558

E-mail address: jhqu@mail.rcees.ac.cn (J.H. Qu).
}

ion-exchange, reverse osmosis and electrodialysis, may concentrate nitrate ions into brine, which has to be treated afterwards. Biological denitrification is currently the most promising technique to solve the nitrate problem. However, possible bacterial contamination, the presence of residual organics, and the possible increase in chlorine demand in purified water [3] limit the application of this process.

Catalytic denitrification is emerging as the most promising and flexible technique for an efficient solution of the problem. In this process, nitrate ions are reduced using hydrogen over bimetallic catalyst. The reaction follows a consecutive reaction scheme in which nitrite is as an intermediate, while nitrogen and ammonia are the final products.

Recently, most of the research in this area has proved that nitrate removal rate and selectivity are strongly influenced by some factors such as metal component [8], the nature of support [9] and preparation procedure of catalysts [7], the $\mathrm{pH}$ value of solution [8], the hydrogen flow rate [10], the reaction temperature [11] and the salt effects [12], etc. The most important factor for the reduction of nitrate is catalytic 
properties of catalyst, which were found to be sensitive to the nature of support and preparation procedure. As for the support, it is generally believed that having adsorptive capability for pollutant is favorable for improving catalytic property of catalyst. However, for general material investigated for nitrate reduction (such as $\mathrm{Al}_{2} \mathrm{O}_{3}, \mathrm{SnO}_{2}$, active carbon, anion resin, membrane), the adsorption performance for nitrate is limited. Therefore, selecting a more suitable catalyst support for the catalytic reduction of nitrate is required. As for the preparation procedure of catalyst for nitrate reduction, the conventional preparation method is impregnation. Nevertheless, this method is not fully reproducible and may give rise to some dishomogeneity of metal distribution on the surface. So the efforts in preparation methods to produce homogeneous distribution of these metals inside the structure of precursors have received many researchers' attention.

Hydrotalcite-type (HT) anionic clays can fulfill these requirements. HT compounds, a class of layered double hydroxides, consist of positively charged metal hydroxide layers separated from each other by anions and water molecules. The chemical composition can be represented by the general formula $\left[\mathrm{M}_{1-x}{ }^{\mathrm{II}} \mathrm{M}_{x}{ }^{\mathrm{III}}(\mathrm{OH})_{2}\right]^{x+}\left[\mathrm{A}^{n-}{ }_{x / n}\right]^{x-} \cdot y \mathrm{H}_{2} \mathrm{O}$, where $\mathrm{M}^{\mathrm{II}}$ and $\mathrm{M}^{\mathrm{III}}$ are divalent and trivalent metal ions, $\mathrm{A}^{n-}$ is an $n$-valent anion, and $x$ can have values approximately between 0.25 and 0.33 . Many investigations showed that a wide range of derivatives containing various combinations of $\mathrm{M}^{\mathrm{II}}$, $\mathrm{M}^{\mathrm{III}}$ and $\mathrm{A}^{n-}$ ions can be synthesized. Marquez et al. [13] demonstrated that copper ions may partially substituted of divalent cations to go into the layer structure of HT. Basile et al. [14] reported that $\mathrm{Pd} / \mathrm{Mg} / \mathrm{Al} \mathrm{HT}$ can be successfully prepared by coprecipitation. So it is possible to synthesize a HT with active metals in the layer structure, which cause high dispersion of active metals. After calcination, homogeneous mixture of oxides with small crystal size is formed. In addition, when calcined hydrotalcites are putted in water solution, they may reconstruct the original layer structure, that is, anions (e.g. nitrate) may enter the interlayer space to compensate the positive charged layers. Because of these properties, HT compounds have attracted considerable attention in recent years in industry, especially as adsorbents [15], catalysts [16] and catalyst supports [17]. For example, some toxic anionic species such as $\mathrm{CrO}_{4}{ }^{2-}, \mathrm{TcO}_{4}{ }^{2-}, \mathrm{SeO}_{3}{ }^{2-}$ and anionic surfactants in water may be significantly adsorbed by HT [18-21]. As catalyst, HT has been used for aldol condensation [22], and reforming of hydrocarbons [23], etc.

For the reduction of nitrate in water, Palomares et al. [17,24] have reported that hydrotalcite-supported $\mathrm{Pd}-\mathrm{Cu}$ catalyst reveals higher activity and selectivity for nitrogen. In our previous study, the performance of adsorption and hydrogenation of nitrate on hydrotalcite-supported $\mathrm{Pd}-\mathrm{Cu}$ catalyst prepared by impregnation has been compared intensively with different supports $\left(\mathrm{Al}_{2} \mathrm{O}_{3}, \mathrm{TiO}_{2}\right.$, and molecular sieve (HZSM)) catalysts at the same $\mathrm{Pd}-\mathrm{Cu}$ loading [25]. The results demonstrated that hydrotalcite-supported $\mathrm{Pd}-\mathrm{Cu}$ catalyst processed higher catalytic activity and selectivity. Based on this result, we further studied the adsorptive and catalytic property for nitrate on hydrotalcite-supported $\mathrm{Pd}-\mathrm{Cu}$ catalysts prepared by impregnation and coprecipitation method, and compared the adsorption with hydrogenation of nitrate to clarify the process of nitrate reduction on hydrotalcitesupported $\mathrm{Pd}-\mathrm{Cu}$ catalyst in this paper.

\section{Experimental}

\subsection{Catalyst preparation}

\subsubsection{Preparation of hydrotalcites support}

Hydrotalcites with different $\mathrm{Mg}$ :Al molar ratios $(x)$ were prepared by coprecipitation at low supersalturation method [26]. In this method, two solutions, A and B, were added dropwise into a beaker containing $100 \mathrm{~mL}$ of deionic water while vigorous stirring. Solution A was $\mathrm{Mg}\left(\mathrm{NO}_{3}\right)_{2}(1.2 \mathrm{~mol} / \mathrm{L})$ and $\mathrm{Al}\left(\mathrm{NO}_{3}\right)_{2}(1.2 / x \mathrm{~mol} / \mathrm{L})$ mixed aqueous solution. Solution B contained $1.65 \mathrm{~mol} / \mathrm{L} \mathrm{NaOH}$ and $0.5 \mathrm{~mol} / \mathrm{L} \mathrm{Na}_{2} \mathrm{CO}_{3}$. During the synthesis process, the $\mathrm{pH}$ of the suspensions was maintained at about 10 . The resulting suspension was then maintained at $25{ }^{\circ} \mathrm{C}$, with stirring for $4 \mathrm{~h}$. The product was filtered, washed thoroughly with deionized water until the $\mathrm{pH}$ of filtrate showed neutral and subsequently dried overnight at $105{ }^{\circ} \mathrm{C}$ and calcined at $550{ }^{\circ} \mathrm{C}$ for $8 \mathrm{~h}$. The final product was mentioned as HTx.

\subsubsection{Preparation of catalyst by co-impregnation}

$\mathrm{Pd}(1.0$ wt.\%)-Cu (0.25 wt.\%)/HTx ( $x$ is $\mathrm{Mg}: \mathrm{Al}$ molar ratios) sample was prepared by co-impregnation method. The HTx powder was putted in an appropriate amount of $\mathrm{Pd}\left(\mathrm{NO}_{3}\right)_{2} \cdot 2 \mathrm{H}_{2} \mathrm{O}$ and $\mathrm{Cu}\left(\mathrm{NO}_{3}\right)_{2} \cdot 3 \mathrm{H}_{2} \mathrm{O}$ mixed aqueous solution. This was followed by evaporation to dryness in a rotary evaporator at $80{ }^{\circ} \mathrm{C}$ under reduced pressure. The resulting paste was dried at $105{ }^{\circ} \mathrm{C}$ overnight, and then calcined in air at $500{ }^{\circ} \mathrm{C}$ for $2 \mathrm{~h}$, finally reduced at $200{ }^{\circ} \mathrm{C}$ for $2 \mathrm{~h}$ under flowing hydrogen/argon. Before catalytic test, the catalyst was seived into 100 meshes. This catalyst was mentioned as $\mathrm{Pd}-\mathrm{Cu} / \mathrm{HT} x$.

\subsubsection{Preparation of catalyst by coprecipitation}

In order to distribute active metals $(\mathrm{Pd}-\mathrm{Cu})$ inside the structure of precursor, an appropriate amount of $\mathrm{Pd}\left(\mathrm{NO}_{3}\right)_{2} \cdot 2 \mathrm{H}_{2} \mathrm{O}$ and $\mathrm{Cu}\left(\mathrm{NO}_{3}\right)_{2} \cdot 3 \mathrm{H}_{2} \mathrm{O}$ mixed aqueous solution was added in the solution A in Section 2.1.1. The palladium and copper contents are 1 and 0.25 wt. $\%$, respectively. Detailed preparation procedure is as in Section 2.1.1. Finally, the sample was also reduced at $200{ }^{\circ} \mathrm{C}$ for $2 \mathrm{~h}$ under flowing hydrogen/ argon. This catalyst was mentioned as $\mathrm{HT} x(\mathrm{Pd}-\mathrm{Cu})$.

\subsection{Catalyst characterization}

The specific surface area (BET method) was determined using an ASAP2000 Surface Analyser (Micromeritics Co., USA) using $\mathrm{N}_{2}$ as the adsorbate.

$\mathrm{X}$-ray powder diffraction (XRD) patterns of samples were obtained with a Bruker diffractometer using $\mathrm{Cu} \mathrm{K} \alpha$ radiation from $10^{\circ}$ to $70^{\circ}$ (in $2 \theta$ ). The measured patterns were compared with PDF data files [27] to confirm phase identities. 


\subsection{Adsorptive and catalytic tests}

All the adsorptive tests in this work were carried out in glass vessels with agitation provided by a shaker at $170 \mathrm{rpm}$ and the temperature was controlled at $25{ }^{\circ} \mathrm{C}$ with air bath. Nitrate solution $(50 \mathrm{~mL})$ at the initial concentration of $100 \mathrm{mg} / \mathrm{L}$ was mixed with $0.1 \mathrm{~g}$ catalyst. Samples were taken at different time intervals.

Catalytic activity and selectivity of different catalyst for nitrate reduction was tested in a thermostated $\left(25^{\circ} \mathrm{C}\right)$ batch reactor equipped with $\mathrm{H}_{2}$ inlet and outlet and a sample port. The catalyst $(1 \mathrm{~g})$ was suspended in pure water $(500 \mathrm{~mL})$, which was saturated with the mixture of argon $(400 \mathrm{~mL} / \mathrm{min})$ and hydrogen $(200 \mathrm{~mL} / \mathrm{min})$ from the titanium plate situated in the bottom of the reactor for $60 \mathrm{~min}$. Solution containing nitrate was introduced and the time was started. The initial nitrate concentration was equal to $100 \mathrm{mg} / \mathrm{L}$.

\subsection{Analysis methods}

Samples were taken from the reactor at desired sampling times and filtered through a $0.45 \mu \mathrm{m}$ membrane. $\mathrm{NO}_{3}{ }^{-}-\mathrm{N}$, $\mathrm{NO}_{2}{ }^{-}-\mathrm{N}$ and $\mathrm{NH}_{4}{ }^{+}-\mathrm{N}$ were determined using a Hitachi-3010 model UV-spectrophotometer.

The actual quantity of active metals of the catalyst was analyzed as follows. Firstly, the catalyst was dissolved in $5 \mathrm{~mol} /$ $\mathrm{L}$ hydrochloric acid solution. Then the solution was diluted for measuring the quantity of $\mathrm{Pd}$ and $\mathrm{Cu}$ in solution by ICP-MASS (VG Co., U.K., PQIII), which is the actual amount of active metals on the support.

\section{Results and discussion}

\subsection{Characterization of catalyst}

The chemical composition and the main characteristics (surface area, average pore volume and pore diameter) of the resulting materials were summarized in Table 1. All the samples prepared by co-impregnation method exhibit similar surface area $\left(183.9-195.0 \mathrm{~m}^{2} / \mathrm{g}\right)$ and similar mesopore structure with an average pore diameter of $47-54 \AA$, which were both lower than that of the catalyst obtained by coprecipitation method (BET: $236.6 \mathrm{~m}^{2} / \mathrm{g}$; average pore diameter $144 \AA$ ). These results indicated that, in our study, the variation of $\mathrm{Mg} / \mathrm{Al}$ molar ratios has no influence on the surface area and pore structure. However, introducing active metals by coprecipitation method may produce an increase of surface area and pore

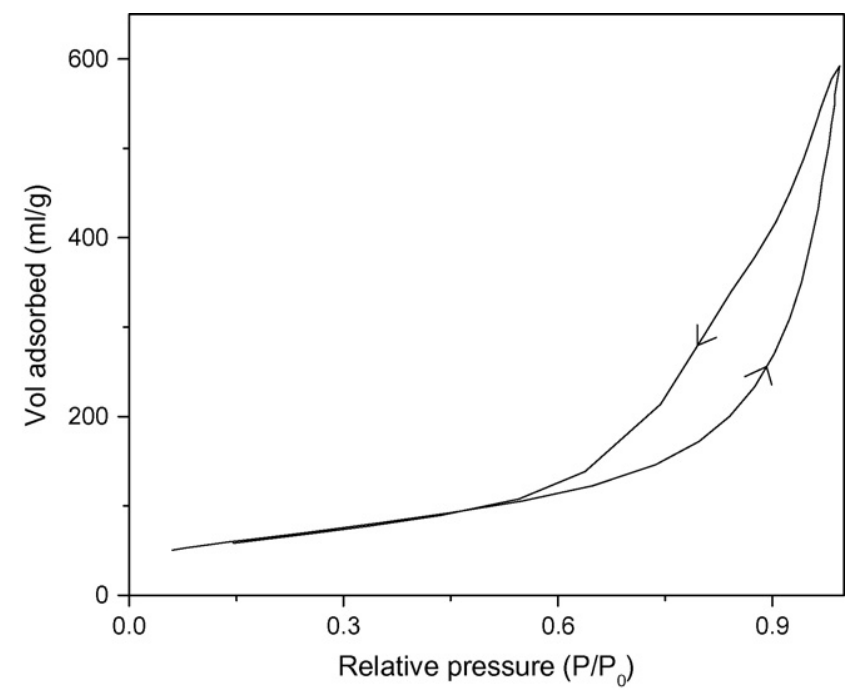

Fig. 1. Nitrogen adsorption-desorption isotherm of HT3(Pd-Cu).

diameter. Additionally, the adsorption-desorption isotherm of HT3(Pd-Cu), shown in Fig. 1, was nearly of type-IV in the classification reported by Brunauer et al. [28]. The hysteresis loop started at a relatively high pressure which supported the mesoporous nature of the sample.

The X-ray diffraction (XRD) analysis was used to identify the composition structures. In Fig. 2, the XRD pattern of the sample prior to calcination showed the presence of a wellcrystallized hydrotalcite phase. After calcination, the peaks corresponding to $\left(\begin{array}{llll}0 & 0 & 3\end{array}\right)$ and $\left(\begin{array}{lll}0 & 0 & 6\end{array}\right)$ planes disappeared, indicating that hydrotalcite structure was changed, while $\mathrm{MgO}$ phase was formed according to the peaks at $43.2^{\circ}$ and $62.7^{\circ}$. In addition, due to the low active metals content, no peak related with $\mathrm{Pd}-\mathrm{Cu}$ could be observed. When the sample was putted in nitrate aqueous solution, the XRD pattern showed that hydrotalcite phase was regenerated. Accordingly, nitrate in water may enter the interlayer of hydrotalcite or be adsorbed on the external surface, which was favorable for the catalytic reduction process.

\subsection{Adsorption capacity for nitrate}

The adsorption kinetics is important as they can provide valuable insights into the mechanism of sorption reactions. Fig. 3 shows the kinetics of $\mathrm{NO}_{3}{ }^{-}$adsorption on different catalysts for an initial $\mathrm{NO}_{3}{ }^{-}$concentration of $100 \mathrm{mg} / \mathrm{L}$. For all the catalysts, the nitrate adsorptions were very fast during the

Table 1

The chemical composition and characteristics of different catalysts

\begin{tabular}{|c|c|c|c|c|c|}
\hline Sample & Pd (wt.\%) & $\mathrm{Cu}($ wt.\%) & $\operatorname{BET}\left(\mathrm{m}^{2} / \mathrm{g}\right)$ & Average pore volume $(\mathrm{mL} / \mathrm{g})$ & Average pore diameter $(\AA)$ \\
\hline $\mathrm{Pd}-\mathrm{Cu} / \mathrm{HT} 2$ & 1.14 & 0.29 & 184.7 & 0.250 & 52.17 \\
\hline $\mathrm{Pd}-\mathrm{Cu} / \mathrm{HT} 3$ & 1.08 & 0.24 & 185.3 & 0.243 & 52.20 \\
\hline $\mathrm{Pd}-\mathrm{Cu} / \mathrm{HT} 4$ & 1.09 & 0.26 & 183.9 & 0.241 & 54.23 \\
\hline $\mathrm{Pd}-\mathrm{Cu} / \mathrm{HT} 5$ & 1.12 & 0.27 & 195.0 & 0.228 & 46.68 \\
\hline HT3(Pd-Cu) & 1.10 & 0.27 & 236.6 & 0.849 & 143.60 \\
\hline
\end{tabular}




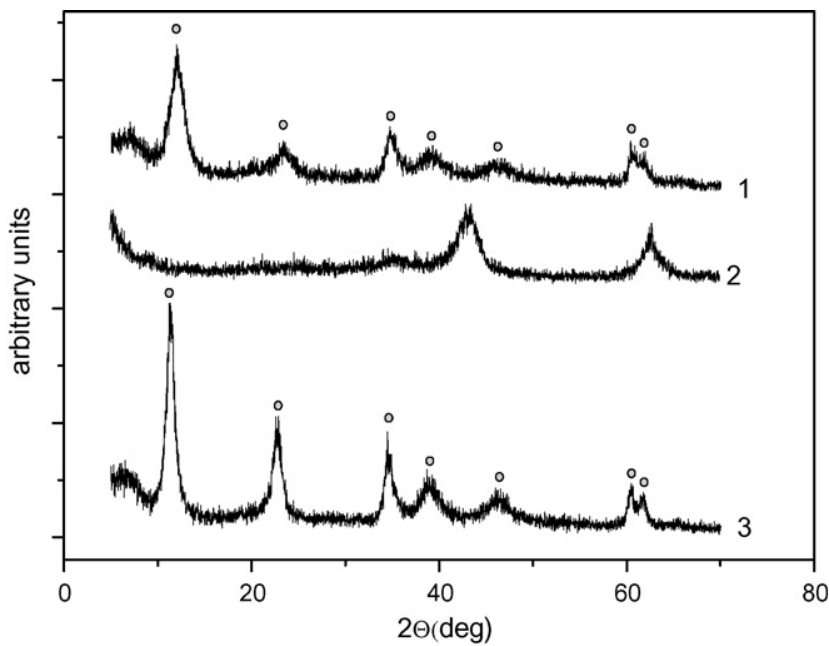

(1) before calcination; (2) after calcination;

(3) contacted with the nitrate aqueous solution

Fig. 2. XRD of HT3(Pd-Cu) catalyst: (1) before calcination; (2) after calcination; (3) contacted with the nitrate aqueous solution.

initial $30 \mathrm{~min}$, and the equilibrium was achieved within $120 \mathrm{~min}$. This behavior has already been reported in the adsorption of other anionic species on hydrotalcite-like compounds [29]. In addition, under the same experimental conditions, the adsorption capacities for various catalysts followed the order: HT3(Pd-Cu) $>$ Pd-Cu/HT5 $>$ Pd-Cu/ HT3 $>$ Pd-Cu/HT2 $>$ Pd-Cu/HT4.

A simple kinetic analysis of adsorption was tested using pseudo-second-order equation. Ho and Mckay [30,31] suggested that, in many cases, kinetics of sorption could be well described by the pseudo-second-order adsorption model, which was based on the assumption that the rate-limiting step was chemisorptions. The pseudo-second-order rate expression was given as:

$\frac{\mathrm{d} q_{t}}{\mathrm{~d} t}=k_{2}\left(q_{\mathrm{e}}-q_{t}\right)^{2}$

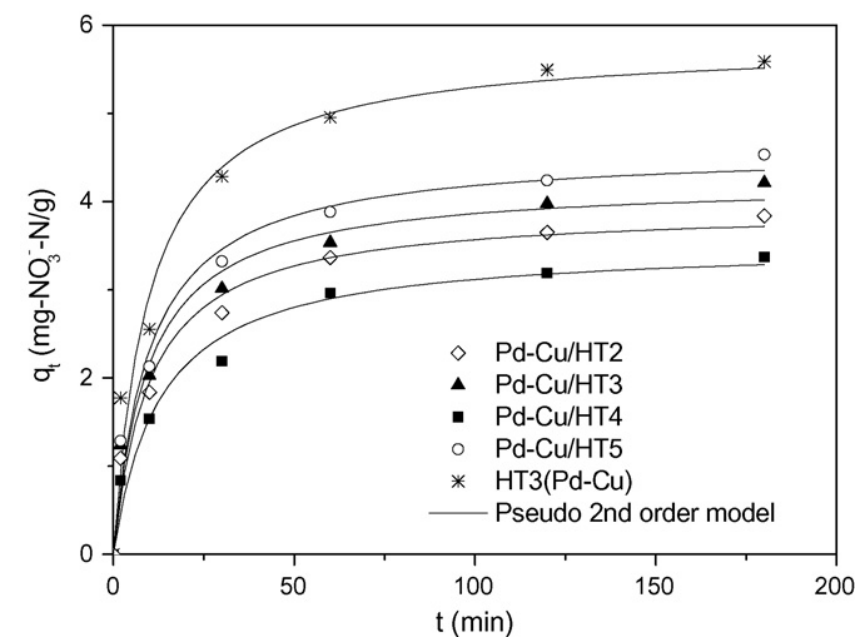

Fig. 3. Adsorption kinetics of $\mathrm{NO}_{3}{ }^{-}$on different catalysts for an initial $\mathrm{NO}_{3}{ }^{-}$ concentration of $100 \mathrm{mg} / \mathrm{L}, 2 \mathrm{~g} / \mathrm{L}$ catalyst, at $25^{\circ} \mathrm{C}$. where $q_{\mathrm{e}}$ and $q_{t}(\mathrm{mg} / \mathrm{g})$ were the amounts of $\mathrm{NO}_{3}{ }^{-}-\mathrm{N}$ adsorbed per gram catalyst at equilibrium and at time $t$, respectively, and $k_{2}(\mathrm{~g} /(\mathrm{mg} \mathrm{min}))$ was the rate constant of pseudo-second-order adsorption. Taking into account the initial sorption rate $v_{0}$ (the amounts of $\mathrm{NO}_{3}{ }^{-}-\mathrm{N}$ adsorbed per gram catalyst and per minute at the initial time $(\mathrm{mg} /(\mathrm{g} \mathrm{min}))$

$v_{0}=k_{2} q_{\mathrm{e}}^{2}$

Eq. (1) can be rearranged to obtain

$\frac{t}{q_{t}}=\frac{1}{v_{0}}+\frac{t}{q_{\mathrm{e}}}$

where the values of $v_{0}$ and $q_{\mathrm{e}}$ can be determined experimentally by plotting $t / q_{t}$ versus $t$.

Obviously, the experimental data in Fig. 3 are in good agreement with the pseudo-second-order model. As shown in Table 2, the correlation coefficients, $R^{2}$, showed high correlation $(>0.97)$ for all the catalysts used in the test, which provided evidence that the overall rate of the $\mathrm{NO}_{3}{ }^{-}$adsorption process appeared to be controlled by chemical processes [32]. Additionally, the initial sorption rate of $\mathrm{NO}_{3}-\left(v_{0}\right)$ and the amounts of $\mathrm{NO}_{3}{ }^{-}$adsorbed at equilibrium $\left(q_{\mathrm{e}}\right)$ onto different catalysts followed the same order of HT3(Pd-Cu) $>\mathrm{Pd}-\mathrm{Cu} /$ HT5 $>$ Pd-Cu/HT3 $>$ Pd-Cu/HT2 $>$ Pd-Cu/HT4, indicating that the catalyst obtained by coprecipitation exhibited a higher adsorption capacity for nitrate than that prepared by the coimpregnation method.

Adsorption capacity at different $\mathrm{NO}_{3}{ }^{-}$concentration can be illustrated by the adsorption isotherm. The experimental data were tested using Langmuir model (Fig. 4), which was based on the assumption that the adsorption occurred on homogeneous surface sites.

The Langmuir sorption model:

$q_{\mathrm{e}}=\frac{q_{\mathrm{m}} b c_{\mathrm{e}}}{\left(1+b c_{\mathrm{e}}\right)}$

where $q_{\mathrm{e}}(\mathrm{mg} / \mathrm{g})$ was the amount of $\mathrm{NO}_{3}{ }^{-}-\mathrm{N}$ adsorbed per gram catalyst at equilibrium, $q_{\mathrm{m}}(\mathrm{mg} / \mathrm{g})$ the maximum adsorption capacity corresponding to complete monolayer coverage, $c_{\mathrm{e}}$ $(\mathrm{mg} / \mathrm{L})$ the equilibrium solute concentration, and $b$ was the equilibrium constant $(\mathrm{L} / \mathrm{mg})$.

The Langmuir model parameters were listed in Table 2. It was evident that, Langmuir model had a good fit with the experimental data for the five catalysts $\left(R^{2}>0.99\right)$. Over the entire concentration range studied, the adsorption of $\mathrm{NO}_{3}{ }^{-}-\mathrm{N}$ by different catalysts is in the order of HT3 $(\mathrm{Pd}-\mathrm{Cu})>\mathrm{Pd}-\mathrm{Cu} / \mathrm{HT} 5>\mathrm{Pd}-\mathrm{Cu} / \mathrm{HT} 3>\mathrm{Pd}-\mathrm{Cu} / \mathrm{HT} 2>\mathrm{Pd}-\mathrm{Cu} /$ HT4. This sequence was the same as the result of kinetic study. Theoretically, the maximum adsorption amount $\left(q_{\mathrm{m}}\right)$ was $9.44 \mathrm{mg}-\mathrm{NO}_{3}{ }^{-}-\mathrm{N} / \mathrm{g}$ for $\mathrm{HT} 3(\mathrm{Pd}-\mathrm{Cu}), 7.01 \mathrm{mg}-\mathrm{NO}_{3}{ }^{-} \mathrm{-N} / \mathrm{g}$ for $\mathrm{Pd}-\mathrm{Cu} / \mathrm{HT} 5,6.22 \mathrm{mg}-\mathrm{NO}_{3}{ }^{-}-\mathrm{N} / \mathrm{g}$ for $\mathrm{Pd}-\mathrm{Cu} / \mathrm{HT} 3,5.46 \mathrm{mg}-$ $\mathrm{NO}_{3}{ }^{-}-\mathrm{N} / \mathrm{g}$ for $\mathrm{Pd}-\mathrm{Cu} / \mathrm{HT} 2$, and $5.44 \mathrm{mg}-\mathrm{NO}_{3}{ }^{-}-\mathrm{N} / \mathrm{g}$ for Pd-Cu/ HT4.

Consequently, there was an appreciate adsorption capacity for $\mathrm{NO}_{3}{ }^{-}$on various hydrotalcite-supported $\mathrm{Pd}-\mathrm{Cu}$ catalysts. The fast $\mathrm{NO}_{3}{ }^{-}$uptake within initial $30 \mathrm{~min}$ indicated that 
Table 2

Kinetic parameters and Langmuir parameters for $\mathrm{NO}_{3}{ }^{-}$adsorption onto different catalysts

\begin{tabular}{|c|c|c|c|c|c|c|c|}
\hline \multirow[t]{2}{*}{ Sample } & \multicolumn{4}{|c|}{ Kinetic parameters } & \multicolumn{3}{|c|}{ Langmuir parameters } \\
\hline & $v_{0}(\mathrm{mg} /(\mathrm{g} \min ))$ & $K(\mathrm{~g} /(\operatorname{mg} \min ))$ & $q_{\mathrm{e}}(\mathrm{mg} / \mathrm{g})$ & $R^{2}$ & $q_{\mathrm{m}}(\mathrm{mg} / \mathrm{g})$ & $b(\mathrm{~L} / \mathrm{mg})$ & $R^{2}$ \\
\hline $\mathrm{Pd}-\mathrm{Cu} / \mathrm{HT} 2$ & 0.392 & 0.0255 & 3.92 & 0.979 & 5.46 & 0.120 & 0.994 \\
\hline $\mathrm{Pd}-\mathrm{Cu} / \mathrm{HT} 3$ & 0.444 & 0.0248 & 4.23 & 0.975 & 6.22 & 0.126 & 0.997 \\
\hline $\mathrm{Pd}-\mathrm{Cu} / \mathrm{HT} 4$ & 0.275 & 0.0222 & 3.52 & 0.978 & 5.44 & 0.081 & 0.993 \\
\hline $\mathrm{Pd}-\mathrm{Cu} / \mathrm{HT} 5$ & 0.469 & 0.0222 & 4.59 & 0.979 & 7.01 & 0.115 & 0.998 \\
\hline HT3(Pd-Cu) & 0.599 & 0.0177 & 5.81 & 0.971 & 9.44 & 0.127 & 0.997 \\
\hline
\end{tabular}

$\mathrm{NO}_{3}{ }^{-}$ions were forced into the interlayer space or adsorbed on the external surface of the hydrotalcite during the regeneration of layer structure. The adsorption capacity for nitrate on the catalyst prepared by the coprecipitation method was apparently higher than that by the impregnation method, which may be due to the intact regeneration of hydrotalcite-like structure for HT3 $(\mathrm{Pd} / \mathrm{Cu})$. Moreover, the adsorption kinetics and adsorption isotherm of all the catalysts were fitted to the pseudo-secondorder model and the Langmuir model, respectively. Thus, it was speculated that the rate-limiting step was chemisorption and adsorption sites were homogeneous.

\subsection{Catalytic hydrogenation activity and selectivity for nitrate}

Generally, different adsorption capacity for $\mathrm{NO}_{3}{ }^{-}$results in different catalytic activity and selectivity of the catalysts in the hydrogenation of nitrate. The variation of $\mathrm{NO}_{3}{ }^{-}$concentration with time during the catalytic hydrogenation of nitrate was shown in Fig. 5. During the initial $2 \mathrm{~min}, \mathrm{NO}_{3}{ }^{-}$concentration decreased rapidly and the removal rates were 12.6, 13.8, 10.1, 15.4, 31.2\% for Pd-Cu/HT2, Pd-Cu/HT3, Pd-Cu/HT4, Pd-Cu/ HT5 and $\mathrm{HT} 3(\mathrm{Pd}-\mathrm{Cu})$, respectively. Then, $\mathrm{NO}_{3}{ }^{-}$removal rate became slow gradually. After $180 \mathrm{~min}$ reaction, the total removal rate for nitrate was $61.9,79.4,47.0,85.4,96.8 \%$ for $\mathrm{Pd}-\mathrm{Cu} / \mathrm{HT} 2, \mathrm{Pd}-\mathrm{Cu} / \mathrm{HT} 3, \mathrm{Pd}-\mathrm{Cu} / \mathrm{HT} 4, \mathrm{Pd}-\mathrm{Cu} / \mathrm{HT} 5$ and HT3(Pd-Cu), respectively. Therefore, the initial removal

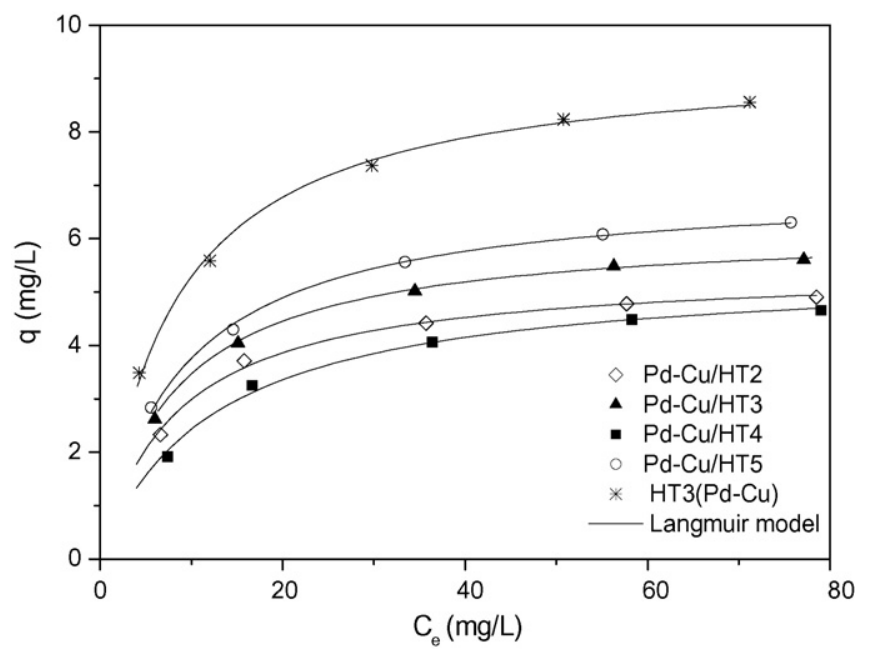

Fig. 4. Adsorption isotherms of $\mathrm{NO}_{3}{ }^{-}$on different catalysts at $25^{\circ} \mathrm{C}$. rate and total removal rate are both in the order of HT3 $(\mathrm{Pd}-\mathrm{Cu})>\mathrm{Pd}-\mathrm{Cu} / \mathrm{HT} 5>\mathrm{Pd}-\mathrm{Cu} / \mathrm{HT} 3>\mathrm{Pd}-\mathrm{Cu} / \mathrm{HT} 2>\mathrm{Pd}-\mathrm{Cu} /$ HT4, which agree well with the result of adsorption. So it could be deduced that higher catalytic activity was attributed to higher adsorption capacity for $\mathrm{NO}_{3}{ }^{-}$. Moreover, the catalyst obtained by coprecipitation showed higher catalytic property for nitrate reduction than that prepared by impregnation, which may be due to different introduction way of active metals. By coprecipitation method, $\mathrm{Pd}-\mathrm{Cu}$ was introduced into the positive charge metal layers of hydrotalcite precursor $[13,14]$, which caused high dispersion of active metals because of the electrostatic expulsive force despite the following high temperature calcinations. For the catalyst obtained by impregnation method, we conferred that $\mathrm{Pd}-\mathrm{Cu}$ active metals were not in the structure of hydrotalcite, but on the surface of the catalyst [17]. Therefore, active metals on the catalyst prepared by coprecipitation method were more homogeneous, which caused higher catalytic activity.

Simultaneously, nitrite and ammonium ions were formed during the catalytic hydrogenation for nitrate (Fig. 6). For the catalysts obtained by impregnation, nitrite increased steadily with nitrate reduction. However, for $\mathrm{HT} 3(\mathrm{Pd}-\mathrm{Cu})$, nitrite increased first, going through a maximum at $88 \%$ of nitrate conversion and then decreased. It could be explained by considering nitrite as an intermediate product of the reduction

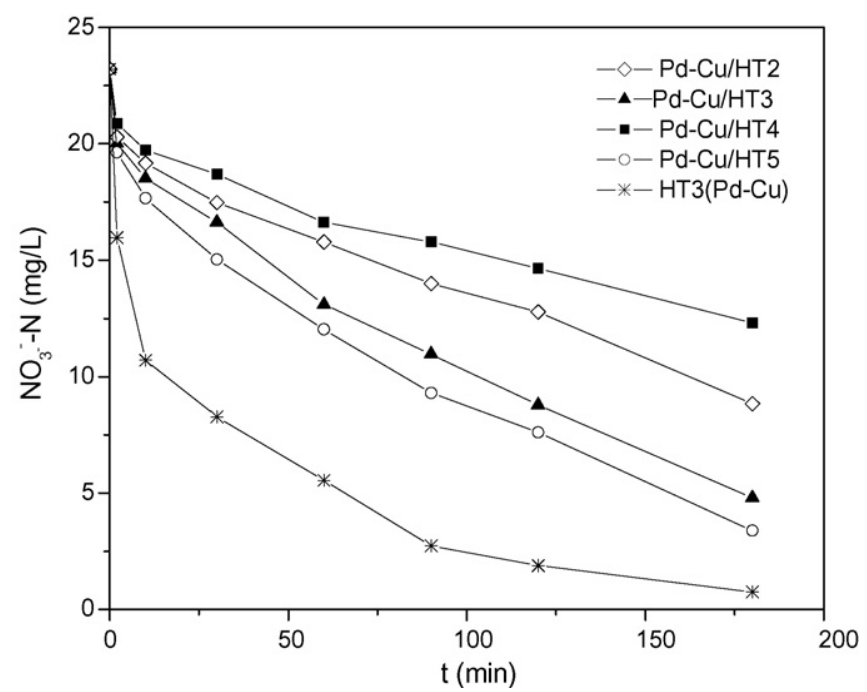

Fig. 5. $\mathrm{NO}_{3}{ }^{-}$concentration with time during the catalytic hydrogenation of aqueous nitrate solution, at $25^{\circ} \mathrm{C}$, without $\mathrm{pH}$ control. 

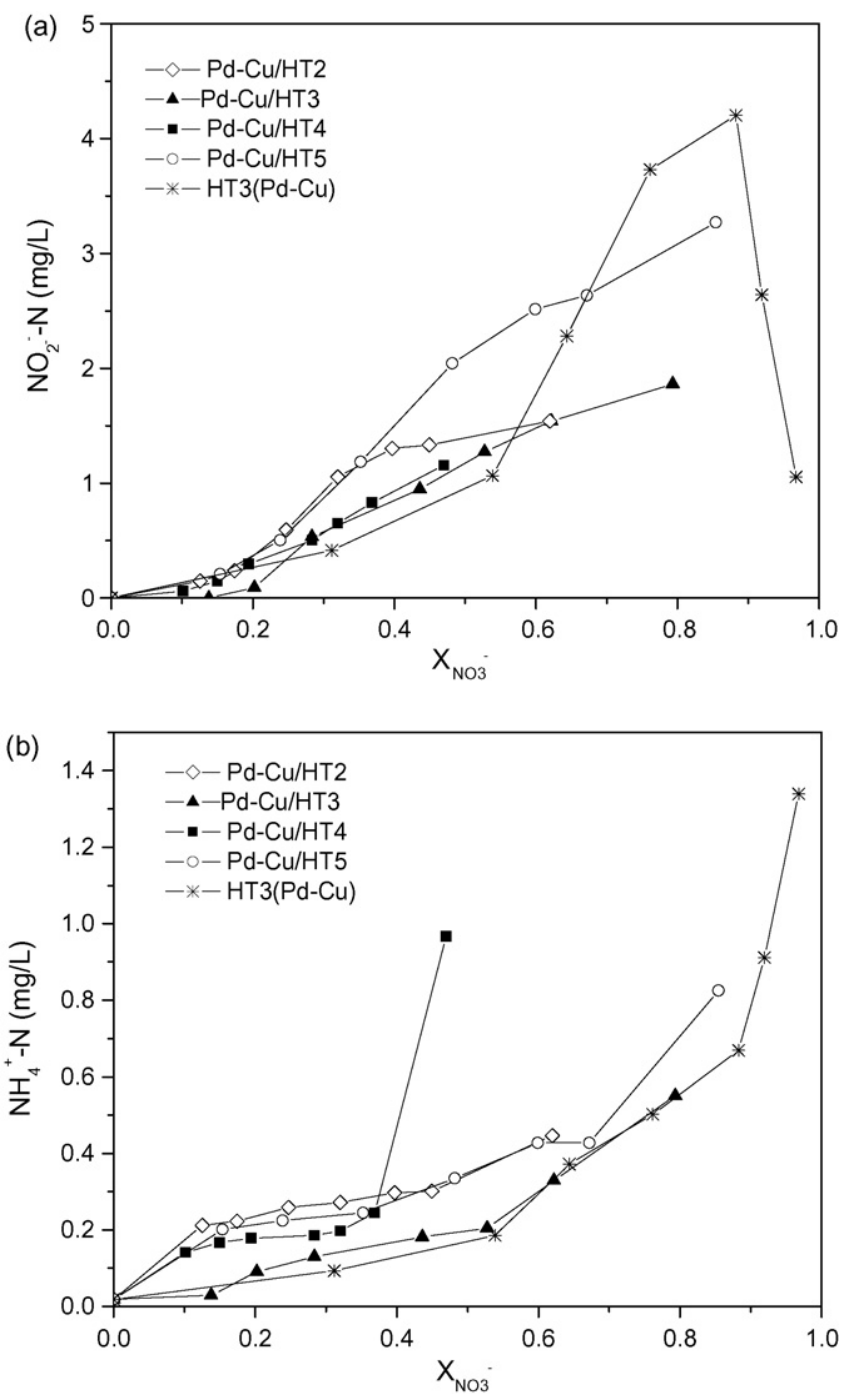

Fig. 6. $\mathrm{NO}_{2}{ }^{-}$(a) and $\mathrm{NH}_{4}{ }^{+}$(b) concentration with $\mathrm{NO}_{3}{ }^{-}$conversion during the catalytic hydrogenation of aqueous nitrate solution, at $25^{\circ} \mathrm{C}\left(X_{\mathrm{NO}_{3}-}=\right.$ $\left(\left[\mathrm{NO}_{3}{ }^{-}\right]_{t=0}-\left(\left[\mathrm{NO}_{3}{ }^{-}\right]_{t}\right) /\left(\left[\mathrm{NO}_{3}{ }^{-}\right]_{t=0}\right)\right.$.

of nitrate. The decline of the nitrite from increase trend resulted from higher catalytic activity for nitrite on HT3(Pd-Cu). Ammonium increased steadily because it was one of final products. At the same nitrate conversion, the lowest $\mathrm{NH}_{4}{ }^{+}$ concentration was formed on HT3(Pd-Cu) catalyst, reaching $1.34 \mathrm{mg}-\mathrm{NH}_{4}{ }^{+}-\mathrm{N} \mathrm{L}^{-1}$ after $180 \mathrm{~min}$ reaction. Therefore, the catalyst prepared by coprecipitation, with the highest adsorption capacity for nitrate, had the best catalytic property for nitrate in our study.

\subsection{Process of combined adsorption with catalytic hydrogenation for nitrate}

In order to further clarify the process of catalytic hydrogenation for nitrate on hydrotalcite-supported $\mathrm{Pd}-\mathrm{Cu}$ catalysts, the amounts of $\mathrm{NO}_{3}{ }^{-} \mathrm{N}$ removal within 30 and 180 min when $\mathrm{H}_{2}$ was provided, were compared with those when no $\mathrm{H}_{2}$ was provided, respectively (Fig. 7). Within the first $30 \mathrm{~min}, \mathrm{NO}_{3}{ }^{-}-\mathrm{N}$ adsorption rates were very fast. The amount of

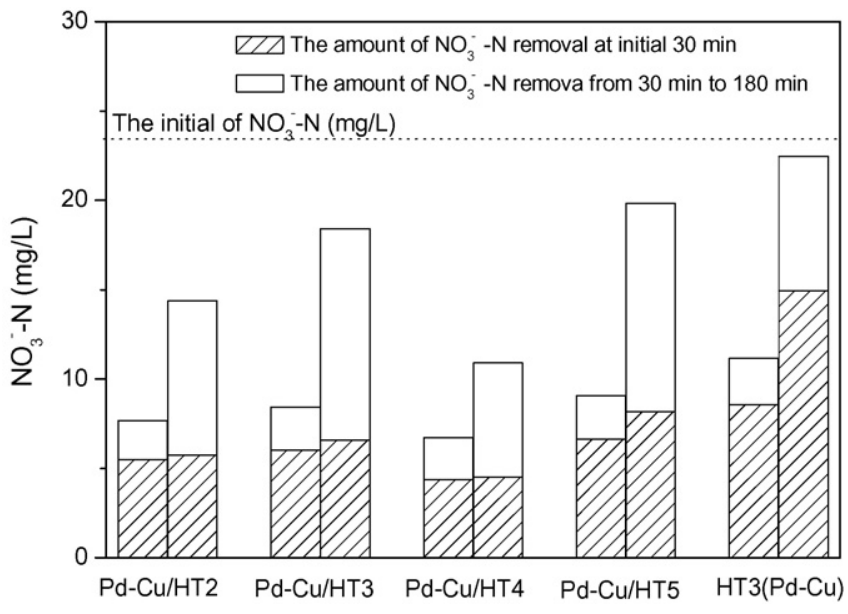

Fig. 7. Comparison of nitrate removal with $\mathrm{H}_{2}$ provided (right column) or not (left column).

$\mathrm{NO}_{3}{ }^{-}-\mathrm{N}$ removal hold $71.35,71.54,64.97,73.33,76.73 \%$ in total $\mathrm{NO}_{3}{ }^{-}-\mathrm{N}$ removal amount within $180 \mathrm{~min}$ for $\mathrm{Pd}-\mathrm{Cu} / \mathrm{HT} 2$, Pd-Cu/HT3, Pd-Cu/HT4, Pd-Cu/HT5 and HT3(Pd-Cu), respectively. Comparably, during the catalytic hydrogenation process, there was only a little increase for nitrate removal on the catalysts except $\mathrm{HT} 3(\mathrm{Pd}-\mathrm{Cu})$. Nevertheless, during the time from 30 to $180 \mathrm{~min}$, the amount of catalytic hydrogenation for nitrate was apparently higher than that of adsorption, which was explained by the high catalytic activity of the catalysts.

On the basis of the above results, a reaction scheme for the catalytic hydrogenation of nitrate on hydrotalcite-supported Pd/ $\mathrm{Cu}$ catalyst was proposed in Fig. 8. Catalytic hydrogenation accompanied with adsorption existed in the process of catalytic reduction for nitrate. Firstly, hydrotalcite structure was reconstructed when calcined catalyst was putted into the nitrate solution. Taking into account the existence of positive charges on the lamellae and also over external surface of hydrotalcite, nitrate may be intercalated rapidly between the brucite-like layers by electrostatic force and adsorbed on the external surface, which resulted in a high adsorption rate at initial time. Simultaneously, nitrate was reduced by $\mathrm{Pd} / \mathrm{Cu}$

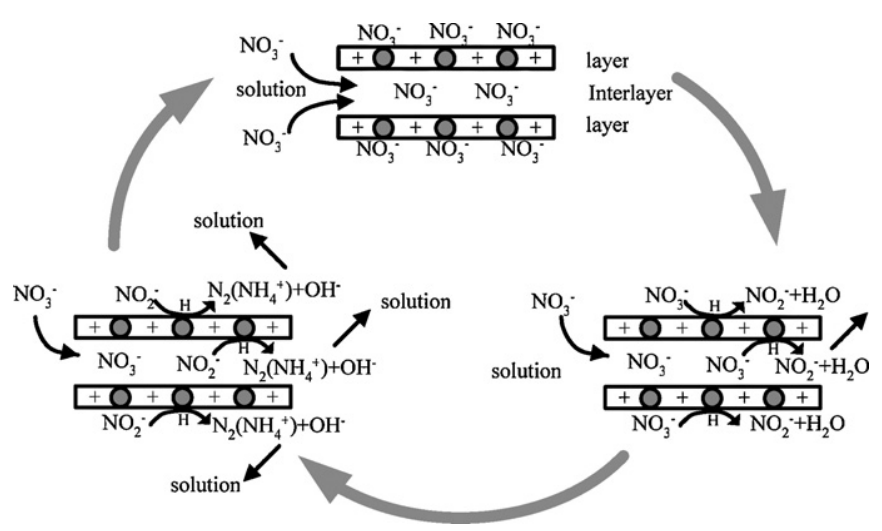

Fig. 8. A reaction scheme for the catalytic hydrogenation of nitrate on hydrotalcites-supported $\mathrm{Pd}-\mathrm{Cu}$ catalysts. 
active sites to nitrite:

$\mathrm{NO}_{3}{ }^{-}+\mathrm{H}_{2} \rightarrow \mathrm{NO}_{2}{ }^{-}+\mathrm{H}_{2} \mathrm{O}$

The nitrite formed would be reduced further to nitrogen:

$2 \mathrm{NO}_{2}{ }^{-}+3 \mathrm{H}_{2} \rightarrow \mathrm{N}_{2}+2 \mathrm{OH}^{-}+2 \mathrm{H}_{2} \mathrm{O}$

During the above reaction steps, the electroneutrality of the system was maintained by the $\mathrm{OH}^{-}$anions produced. Whereafter, nitrate in the solution was continuously adsorbed through ion-exchange with $\mathrm{OH}^{-}$, which was followed by the catalytic hydrogenation process. A new reaction cycle would start. However, considering the slower rate of adsorption through ionexchange than that by electrostatic force in the initial time, adsorption rate declined. Additionally, the accumulation of $\mathrm{OH}^{-}$ suppressed the catalytic hydrogenation reaction. Therefore, both adsorption rate and catalytic hydrogenation rate decreased gradually until achieving equilibrium, and this process maintained during the nitrate reduction. Finally, when the concentration of nitrate ions in solution was very low, nitrate ions adsorbed on the catalyst continued to be catalytically reduced. Therefore, the nitrate removal on hydrotalcites-supported $\mathrm{Pd}-\mathrm{Cu}$ catalysts, with $\mathrm{H}_{2}$ provided, was a consecutive and dynamic adsorption and catalytic hydrogenation process.

\section{Conclusions}

The hydrotalcite-supported $\mathrm{Pd}-\mathrm{Cu}$ catalysts showed effective adsorptive and catalytic properties for nitrate. These results may be related with the characteristics of hydrotalcite which, after calcination, reconstructed its layer structure when contacting nitrate solution. During the regeneration of layer structure, nitrate ions were forced to enter the interlayer space and adsorbed on the external surface of hydrotalcite, then, to be reduced further. The adsorption kinetics and the adsorption isotherm of all catalysts were in good agreement with the pseudo-second-order model and the Langmuir model, respectively, which indicated that the rate-limiting step was chemisorption and adsorption sites were homogeneous.

The same order of catalytic activity and adsorption capacity demonstrated that higher catalytic reduction efficiency was caused by higher adsorption capacity for $\mathrm{NO}_{3}{ }^{-}$. In addition, the catalyst, obtained by coprecipitation method, showed higher adsorptive and catalytic activity than that prepared by impregnation, which was due to the intact regeneration of hydrotalcites-structure and homogeneous distribution of active metals. The comparison of catalytic reduction with the adsorption showed that the catalytic hydrogenation of nitrate on hydrotalcites-supported $\mathrm{Pd}-\mathrm{Cu}$ catalysts was a consecutive and dynamic adsorption and catalytic hydrogenation process.

\section{Acknowledgements}

This work was supported by the Funds for Creative Research Groups of China (Grant No.50621804) and National High Technology Research and Development Program of China (Grant No. 2006AA06Z302).

\section{References}

[1] Y. Sakakibara, K. Araki, T. Watanabe, M. Kuroda, Water Sci. Technol. 36 (1997) 61.

[2] A. Pintar, Catal. Today 77 (2003) 451.

[3] A. Kapoor, T. Viraraghavan, J. Environ. Eng. 4 (1997) 371.

[4] O.M. Flere, T.C. Zhang, J. Environ. Eng. 125 (1999) 721.

[5] B.E. Rittmann, P.M. Huck, CRC Crit. Rev. Environ. Control 19 (1989) 119.

[6] S. Hörold, K.D. Vorlop, T. Tacke, M. Sell, Catal. Today 17 (1993) 21.

[7] U. Prusse, M. Hahnlein, J. Daum, K.D. Vorlop, Catal. Today 55 (2000) 79.

[8] U. Prusse, K.D. Vorlop, J. Mol. Catal. A: Chem. 173 (2001) 313.

[9] Y. Yoshinaga, T. Akita, I. Mikami, T. Okuhara, J. Catal. 207 (2002) 37.

[10] Y.X. Chen, Y. Zhang, H.Y. Liu, J. Environ. Sci. 15 (2003) 600.

[11] G. Centi, S. Perathoner, Appl. Catal., B: Environ. 41 (2003) 15.

[12] A. Pintar, S. Marko, J. Levec, J. Catal. 174 (1998) 72.

[13] F. Marquez, A.E. Palomares, F. Rey, A. Corma, J. Mater. Chem. 11 (2001) 1675.

[14] F. Basile, G. Fornasari, M. Gazzano, A. Vaccari, Appl. Clay Sci. 16 (2000) 185.

[15] S. Yata, Clays Clay Miner. 31 (1983) 305.

[16] T.M. Jyothi, T. Raja, B.S. Rao, J. Mol. Catal. A: Chem. 168 (2001) 187.

[17] A.E. Palomares, J.G. Prato, F. Rey, A. Corma, J. Catal. 221 (2004) 62.

[18] S.W. Rhee, M.J. Kang, H. Kim, C.H. Moon, Environ. Technol. 18 (1997) 231.

[19] M.J. Kang, K.S. Chun, S.W. Rhee, Y. Do, Radiochim. Acta 85 (1999) 57.

[20] Y.W. You, G.F. Vance, H.T. Zhao, Appl. Clay Sci. 20 (2001) 13.

[21] P.C. Pavan, E.L. Crepaldi, G. Gomes, A. De, J.B. Valim, Colloids Surf. A 115 (1999) 399.

[22] P. Kuśtrowski, D. Sułkowska, L. Chmielarz, R. Dziembaj, Appl. Catal., A: Gen. 302 (2006) 31.

[23] K. Nagaoka, A. Jentys, J.A. Lercher, J. Catal. 229 (2005) 18.

[24] A.E. Palomares, J.G. Prato, F. Marquez, A. Corma, Appl. Catal. B 41 (2003) 3 .

[25] Y. Wang, J.H. Qu, R.C. Wu, H.J. Liu, Chin. Sci. Bull. 51 (2006) 1431.

[26] F. Cavani, F. Trifiro, A. Vaccari, Catal. Today 11 (1991) 203.

[27] T.L. Evstigneeva, A.D. Genkin, Can. Mineral. 21 (1983) 481.

[28] S. Brunauer, D.W. Deming, L.S. Deming, E. Teller, J. Am. Chem. Soc. 62 (1940) 1723.

[29] O.P. Ferreira, S.G. Moraes, N. Duran, L. Cornejo, O.L. Alves, Chemosphere 62 (2006) 80.

[30] Y.S. Ho, G. McKay, Chem. Eng. J. 70 (1998) 115.

[31] Y.S. Ho, G. McKay, Process Biochem. 34 (1999) 451.

[32] Y.S. Ho, G. Mckay, Water Res. 34 (2000) 735. 